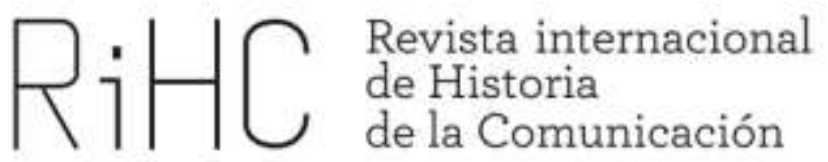

\title{
EL ALMANAQUE DE LAS PROVINCIAS. CRÓNICA VIVA DE UNA CIUDAD EN TRANSICIÓN (1970- 1980)
}

DOI: http://dx.doi.org/10.12795/RiHC.2016.i07.06

Ana María Cervera

Universidad de Valencia

amcervera28@hotmail.com

Enviado: $30-5-2016$

Aceptado: 28-10-2016

Resumen: El Almanaque de Las Provincias es una publicación centenaria que podemos enmarcar tanto en el género de revista literaria como en el tradicional almanaquecalendario entregado por los periódicos a sus suscriptores como regalo. En este caso, editado por el diario Las Provincias, decano de la prensa en Valencia, supone una miscelánea de textos (ensayos, artículos, reportajes, poemas), al tiempo que resume lo esencial del año periodístico. El prestigio de sus colaboradores es indiscutible, y el valor histórico de sus páginas, imprescindible para abordar el estudio de 150 años de la vida valenciana. Este trabajo se centra en una década esencial en nuestro pasado más reciente: los años 70, que marcaron el tránsito entre el franquismo y la transición a la democracia, en los que el diario Las Provincias jugó un importantísimo papel, y su Almanaque nos deja un testimonio de primer orden para la investigación histórica.

Palabras clave: Prensa, Almanaque, Transición, Valencia 


\begin{abstract}
The Almanaque de Las Provincias is a hundred year old publication which can be regarded as a literary magazine as well as the traditional calendar given by the newspapers as a gift for their subscribers. This one in particular, edited by the journal Las Provincias, the oldest diary in Valencia, is a mixture of tests (essays, articles, reports, poems) that summarizes the most important information of the year. With well known journalists and writers, its historical value is irreplaceable in the study of 150 years of Valencian life. This work regards an essential decade in our most recent past: the seventies, which supposed the transition between the dictatorship and the democracy, when Las Provincias played an important role. Its Almanaque leaves us a first class testimony for historical research.
\end{abstract}

Key words: Press, Calendar, Transition, Valencia

\title{
1 Planteamiento del estudio. Estado de la cuestión
}

El presente trabajo tiene por objeto rescatar del olvido una publicación señera en la historia del periodismo valenciano: El Almanaque de Las Provincias. Si bien existen estudios relevantes sobre la prensa en Valencia, especialmente desde el campo de la Comunicación, no es así desde el punto de vista de la Historia, sobre todo en la etapa que media entre el final del franquismo y la Transición. A ello se une un vacío aún mayor: el que se refiere a la prensa literaria valenciana, de la que el Almanaque es un singular referente.

Las obras sobre la prensa española en la transición a la democracia son numerosas: Antonio Alférez sobre el "cuarto poder" en España, Carlos Barrera sobre Periodismo y Franquismo, Jaume Guillamet, con sus estudios sobre Prensa, Franquismo y Autonomía o el reciente estudio sobre el periodismo en las transiciones políticas; los trabajos de María Cruz Seoane sobre Historia de la Prensa Española y la obra de Carmen Castro, historiadora que reivindica "el aporte de la prensa al proceso democrático durante el segundo franquismo y la Transición", para "desplazar el objetivo desde la esfera de las élites políticas hacia el ámbito de la prensa, como factor de cambio en el proceso democratizador" (Castro, C.: 2010, 25).

En cuanto a la historia de la prensa valenciana, desde los años 80 los estudios sobre periódicos y periodistas han ido girando, progresivamente, hacia una integración de la investigación en los contextos económicos, sociales, culturales y políticos, aunque con la carencia de estudios sobre las propias empresas editoras. Hasta hace pocos años, el único estudio sobre el diario Las Provincias era más bien una historia cronológica del periódico con tintes hagiográficos, firmada por el profesor de la antigua Escuela de Periodismo, y periodista veterano, José Altabella. 
En 1995 aparece un trabajo de Rafael Xambó, plasmado a través de entrevistas a un completo "quién es quién" en los medios valencianos en la Transición. Posteriormente, contamos con el exhaustivo trabajo de Luis Amador Iranzo, donde resalta el papel central que tuvo Las Provincias y su subdirectora durante la Transición valenciana.

Anna Mateu y Martí Domínguez han estudiado una parte del discurso de Consuelo Reyna, y su influencia para condicionar políticamente la sociedad valenciana. Y más recientemente, los trabajos de Verónica Roselló sobre dos diarios en Cataluña (L'Avui y La Vanguardia) y en el País Valenciano (Levante-EMV y Las Provincias) y su aportación a la construcción identitaria nacional; el estudio de Carles Senso sobre "Valencia Semanal" en la transición valenciana y la publicación de la tesis de María Pareja Olcina sobre el diario Mediterráneo de Castellón.

Pero sin duda, para la etapa y el espacio que nos ocupa, el estudio de referencia es la obra de Enrique Bordería, que pretende aportar, desde el estudio de los periódicos valencianos, una explicación global del periodismo a nivel nacional en la larga etapa franquista.

Centrándonos en El Almanaque de Las Provincias, el diario decano editaba cada año un resumen de todo lo publicado en sus páginas, a modo de anuario o revista de prensa, que recogía las noticias aparecidas bajo su cabecera.

Si bien no se trata estrictamente de una publicación literaria, podemos hablar de una miscelánea en cuanto a temas y autores, en cuyas páginas se aunaba el repaso a la vida valenciana del año, en forma de crónica periodística o breves apuntes por fechas, junto a un importantísimo espacio reservado a la creación, a la crítica literaria y al repaso erudito de artes escénicas, musicales o pictóricas. En sus páginas se daban cita no sólo firmas de la propia redacción del periódico, como también colaboradores de muy distinta índole, tanto cultural como ideológica. Y, lo que es más destacable, bilingüe, incluso desde la primera década de posguerra. En 1944 publica Joan Fuster en El almanaque de Las Provincias el primer artículo escrito en catalán: "Veinticinco años de poesía valenciana".

Precisamente a los años de posguerra, entre 1940 y 1951, se refiere un trabajo del filólogo Santi Cortés Carreres, sobre la prensa literaria valenciana en esas décadas, y especialmente del Almanaque, estudiando la evolución de la publicación desde el final de la guerra civil hasta años posteriores en que el espíritu del suplemento anual intenta encauzarse a sus orígenes: "integracionista" y finalmente, "localista", volviendo a rescatar la esencia de lo que el periódico -y el Almanaque- consideran "lo valenciano".

Tras el citado estudio, centrado en los años "duros" del franquismo, pretendemos en este trabajo abordar una intensa etapa, que lo fue tanto para el propio rotativo como para la historia política y social valenciana: los años que median entre el final del 
franquismo y la transición a la democracia. Una década, los años 70, de cambios económicos, de inminencias políticas, de aspiraciones locales frente al poder central, de ensanchamiento de las clases medias; una época, sobre todo desde 1972, en que Las Provincias pasa a ser el referente valenciano del aperturismo.

Si la etapa conocida como "primavera de Las Provincias" se advierte en sus páginas diarias, hay que abordar cómo se manifiesta en su inseparable Almanaque, que esperaban año tras año sus suscriptores. Se trataba de la cita anual de una publicación que Teodoro Llorente Falcó definió en 1933 como "una obra que es una Institución”.

Para ello, se han estudiado los volúmenes entre 1970 y 1980, para determinar su contenido y evolución: estructura, temas, firmas propias del periódico, colaboradores externos, fotografía, diseño de portada, e incluso publicidad interior y de contraportada.

\section{El Almanaque, un "regalo" inseparable de Las Provincias}

Con la inspiración de las publicaciones populares desarrolladas en el XVIII por la pujante burguesía de las ciudades, El Almanaque de Las Provincias se edita por primera vez en 1880, catorce años después del nacimiento del periódico, cuando se regala a los suscriptores, tal como ya habían hecho algunos periódicos en España; y no ha faltado a la cita anual con la historia de Valencia de la mano del diario decano, cubriendo la crónica de tres siglos de la ciudad, con la única interrupción reseñable entre los años 1937 a 1939.

El primer almanaque hacía un repaso a cada uno de los sucesos políticos valencianos de 1879. Comenzaba con un calendario-santoral para 1880, después la previsión meteorológica para cada mes y proseguía con artículos de opinión sobre diversos acontecimientos valencianos de carácter cultural, social o político firmados por las figuras más relevantes de la vida valenciana. Finalizaba con las necrológicas de los personajes más ilustres de la ciudad. Esta estructura se ha venido repitiendo a lo largo de toda su existencia.

Con una personalidad propia como publicación por su interés literario y cultural, amén de crónica anual, es interesante abordar la evolución, contenidos y colaboradores de este Almanaque que año tras año reunía tanto un resumen de los temas y sucesos más reseñables en Valencia, como una auténtica selección de firmas literarias, económicas y políticas dentro del menguado panorama cultural de los largos años del franquismo y de la vida de provincias. 
Francisco Pérez Puche, veterano periodista del diario, recuerda que "durante su larga historia, todos los grandes asuntos de la política, los cambios sociales, los sucesos, las bellas artes y la economía han desfilado por sus páginas, que son un destilado de cuanto ha ocurrido cada año en la ciudad y en la región valenciana. Acompañando ese desfile de hechos, poesía, cuentos, teatro y reseñas de historiadores, cronistas, poetas e investigadores nos sirven para tener, en cada momento, el pulso y las tendencias de la sociedad valenciana" ("No hay historia de Valencia sin el Almanaque de Las Provincias", Las Provincias, 30-01-14).

El Almanaque era "una mena de calaix de sastre on podem trovar una gran diversitat d'articles i d'informacions" (Cortés, 1991: 42). El cronista Almela Vives afirmaba que "cuando llega a nuestras manos un nuevo volumen de El Almanaque de Las Provincias nuestra palabra o nuestra pluma tiende a resolverse inmediatamente en el elogio... material indispensable para futuros historiadores; alabanza a los trabajos de índole literaria; alabanza a la amplitud con que se hallan abiertas sus páginas a los colaboradores jóvenes..." (Cortés, 1991: 43) y Manuel Sanchis Guarner lo definía como "la publicación que puede gloriarse de haber sido el tradicional portavoz anual de los eruditos amadores de las cosas genuinamente valencianas" (Cortés, 1991: 43).

Genuinamente valenciano es el propio diario, que en 1966, cuando celebra su centenario, figuraba en cuarto lugar entre los rotativos españoles por antigüedad, sólo precedido por El Diario de Barcelona, El Faro de Vigo y El Norte de Castilla. El director en aquella efeméride José Ombuena, lo evoca con el titular "Un periódico para todos los valencianos". En su antigua redacción se forjaron los nombres de la mejor época de la Renaixença valenciana, y se recogía en sus páginas la ilusión de alcanzar el espíritu de tolerancia que en los años de su nacimiento se echaba de menos en la azarosa vida política de la Restauración.

\section{3 "No se podrá escribir la historia moderna de Valencia sin consultar este Almanaque» (T. Llorente Falcó)}

El primer director del Almanaque hasta 1905 fue el fundador y director del propio periódico, el poeta Teodoro Llorente Olivares. Tras él, se hizo cargo de la dirección Teodoro Llorente Falcó, y a partir de 1949 hasta 1958, Martín Domínguez Barberá. Desde 1958 ocupa la dirección tanto del diario como del Almanaque José Ombuena, hasta que a mediados de los años 70 se hace cargo de la edición anual la recién incorporada subdirectora María Consuelo Reyna. Desde entonces, el almanaque se 
editará a principios de enero, en lugar del mes de junio como venía saliendo hasta entonces.

En el marco de los años 70, Las Provincias, empresa familiar, imprenta, editorial y periódico decano de la ciudad, de ideología liberal conservadora, es la cabecera de referencia de la burguesía de la capital, aunque manteniendo desde sus orígenes una vocación "regional"; en el caso del periódico, en modo alguno como un regionalismo arcaico o nostálgico, sino más bien como esencia de una visión de desarrollo y futuro autóctono aunque basado en raíces culturales e históricas.

Tras unos años de cierto enfrentamiento con el poder central, reflejado en la dimisión forzada del director Martín Domínguez en 1958, el rotativo, dirigido por José Ombuena, empieza a afianzar su influencia y expansión económica, de manera lenta y minuciosa. Sin enfrentamientos con la censura, en parte gracias a la discreción y buenas relaciones del director, a finales de los años 60 la empresa editora despega y las ventas del diario superan año tras año a su oponente en la ciudad, el diario Levante.

Desde los primeros 70, el periódico apuesta de forma explícita por la integración en el Mercado Común y por la adecuación política y democrática a los países desarrollados. Por otro lado, son años en los que se produce una expansión urbanística sin precedentes, impulsada desde el poder central, que amenaza de forma grave tanto al rico entorno de huerta de la capital, como al propio patrimonio histórico artístico y monumental.

Las Provincias asume de manera convencida la defensa del patrimonio y del entorno natural, encabezando señaladas campañas contra la deforestación y urbanización de la Dehesa del Saler, la petición de zona verde para el antiguo cauce del rio Turia, y la reivindicación del valor artístico del patrimonio arquitectónico de la ciudad.

La cruzada de defensa del entorno natural del Saler supone para el diario valenciano el reconocimiento como el primer periodismo medioambiental en el ámbito de los géneros de opinión escrita (Mateu y Domínguez, 2011: pp.171-187). Son campañas en las que se empeñó de forma editorial todo el periódico, y de manera personal María Consuelo Reyna, recién incorporada a la subdirección en 1972.

Consuelo Reyna, joven periodista hija de la familia propietaria de Las Provincias, marca con su impronta personal y su estilo directo, toda una época en la historia del periodismo valenciano: controvertida, influyente, creadora de opinión, gestora de "batallas" y de líderes políticos. En ella recayó, recién incorporada, la confección del Almanaque: "Creo que fue a mediado de los setenta cuando el director me encargó que me hiciera cargo de él para conseguir que saliera en enero con un resumen del año y una selección de los artículos más significativos publicados". 
Para la periodista, "era el almanaque con mismo formato y espíritu desde su nacimiento más antiguo de Europa", y repasando textos y colaboradores observaremos temas, firmas y artículos en las que aparece patente el espíritu de renovación y apertura que la llegada de Reyna, de jóvenes periodistas y de la propia evolución de la empresa editora, volcaron en la centenaria publicación.

El esfuerzo de adaptación de la empresa al cambio que se atisbaba; la profesionalidad de periodistas señeros y de los recién llegados, junto a la reivindicación de "lo valenciano", se transmitieron día a día desde el periódico, y año a año en una publicación, el Almanaque, el regalo esperado de un público fiel.

\title{
4 1970-1980: El Almanaque de las Provincias. Crónica de un cambio
}

\begin{abstract}
Ho pense i ho dic perque, justament ara, acaba d'aparèixer un "almanaque": el d'enguany... que torna a donar una visió amplia i plena del que ha estat, no sols un any d'activitats valencianes, sinó un any de preocupacions de les nostres gents... Torna així l'almanac a una línia oberta d’atenció i de preocupació...

Perque l'almanac... pense que es fa exclusivament en atenció a aqueix compromís cívic concret amb una comunitat concreta.
\end{abstract}

Vicent Andrés Estellés

(“L'Almanac”, Almanaque de las Provincias, 1974, pp.373-374)

El escritor y periodista Vicente Vidal Corella ("El primer almanaque de Las Provincias", Almanaque de Las Provincias, 1974, pp.395-398) recuerda que el deseo del fundador Teodoro Llorente en su Almanaque era que en sus páginas "se reflejase la vida valenciana de una manera total, sin partidismos de ninguna clase... el director solicitaba la colaboración de literatos, historiadores y científicos, que accedían gustosos por el prestigio de la publicación".

El Almanaque de Las Provincias había cumplido 92 ediciones cuando Andrés Estellés, Jefe de Redacción del rotativo, intelectual comprometido y poeta renovador de la literatura contemporánea en valenciano firmaba su artículo. Desde 1880 hasta el 
calendario de 1972, la estructura de sus páginas se había mantenido prácticamente inalterable:

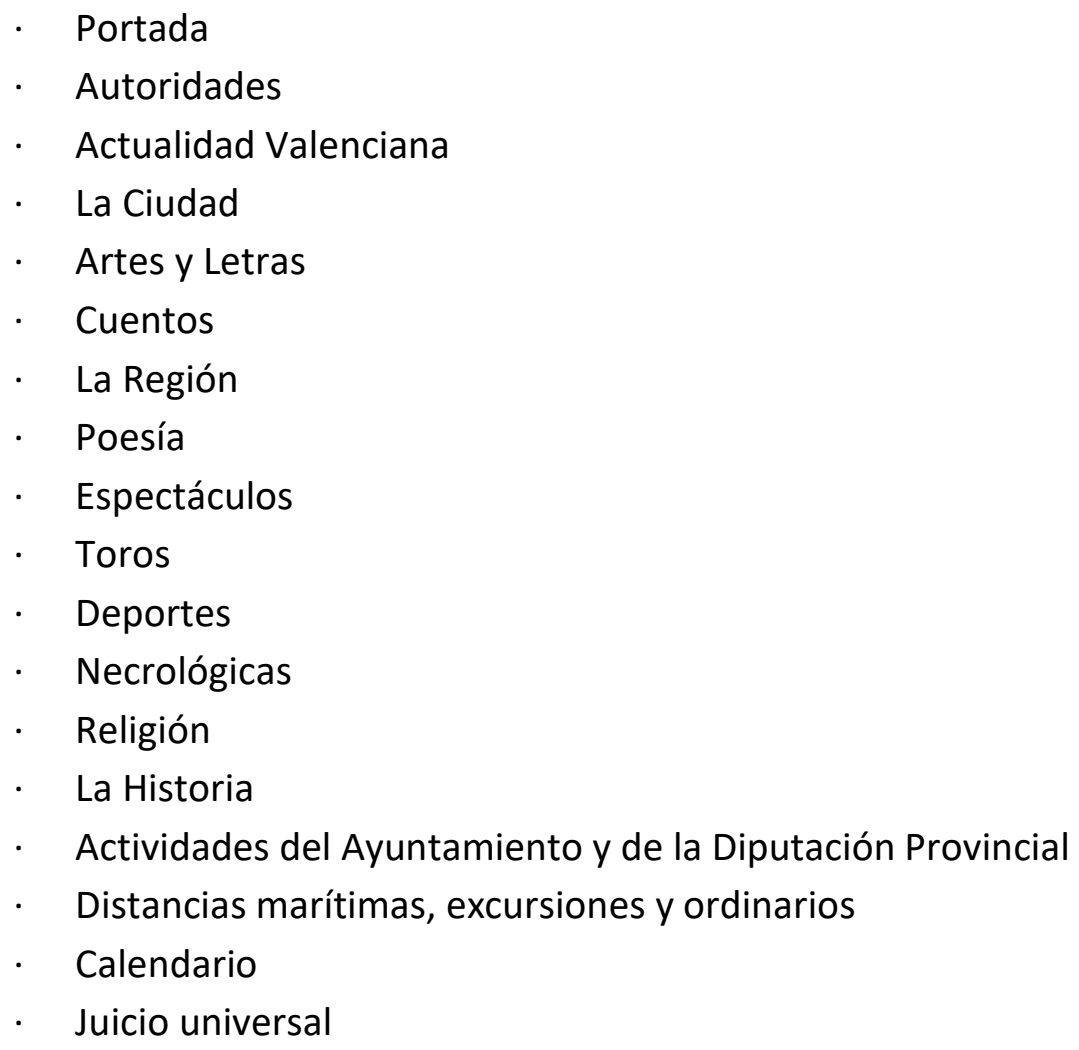

Una estructura inalterable, como inalterable era la línea del periódico para sus lectores, que recoge hasta entonces la "fotografía" de una larga época y el retrato formal de una determinada clase social: la burguesía valenciana que buscaba cada mañana en el periódico la información social local, los apuntes históricos valencianos, las páginas de religión, las imprescindibles necrológicas, la reseña de espectáculos y unos breves apuntes políticos y económicos.

A ello se añade secciones que corresponderían expresamente a las páginas de un almanaque, como colaboraciones literarias, calendario, datos geográficos y de turismo local y el curioso "Juicio Universal" meteorológico-astronómico.

Sin embargo, la historia marca un cambio en los años 70. España desde la década anterior busca un acomodo en el marco internacional que de cabida a una economía en expansión y una salida institucional "moderna" aunque sin tocar los principios generales del Movimiento. La cultura y la sociedad empiezan a caminar en paralelo al inmovilismo del poder, recogiendo influencias externas que ya nadie puede obviar.

1969 es un año de transición tras la convulsión del 68 en el mundo desarrollado: En España, se abandona definitivamente Ifni, se declara en Madrid la Ley Marcial y Franco proclama a su sucesor, Juan Carlos de Borbón, el 22 de julio, mientras un día antes, el 21, el hombre llega a la Luna. Desde entonces, posiblemente el Juicio Universal meteorológico-astronómico del Almanaque haya quedado obsoleto. 


\subsection{9-1973: Todo cambia, nada permanece}

El historiador de la comunicación Enrique Bordería sostiene que desde la Ley Fraga, que inicia una etapa informativa de relativa y condicionada libertad, el comportamiento de la prensa valenciana, al contrario que en Madrid o Barcelona, fue prudente y acomodaticio (Bordería, E.: 2000, p.256). Una posición que favorecerá a Las Provincias, cuyas cifras entre 1967 y 1971 la sitúan ya ligeramente por encima del diario del Movimiento, Levante. Frente al retraso tecnológico de la prensa gubernativa, la bonanza económica y la paz del diario decano con las autoridades, relanza a la empresa editora, que amplía capital social y empieza a buscar ampliar lectores fuera de la capital, estableciendo corresponsales en poblaciones importantes de las tres provincias (Gandía, Denia, Xàtiva, Burriana). Busca incluso captar a profesionales de su rival. El propio Ombuena provenía de Levante, y en 1967 se incorpora desde aquel periódico una periodista señera en la redacción de Las Provincias, María Ángeles Arazo.

En este marco, El Almanaque de 1969, cuya fotografía de portada muestra las obras de lo que entonces se llamaba "La Solución Sur", el nuevo cauce del Turia inaugurado en diciembre 12 años después del desastre de la riada del 57, abre sus páginas con el capítulo AUTORIDADES y la dimisión de una personalidad clave en los años 60 de la ciudad: el alcalde Adolfo Rincón de Arellano, falangista, individualista, personalidad singular que marcó un antes y un después en la vida municipal, e indirectamente, en el devenir del propio periódico.

Llega al Ayuntamiento en 1958, tras la crisis provocada por las críticas del anterior alcalde Tomás Trénor, Marqués del Turia, y del director de Las Provincias, Martín Domínguez, por la falta de ayudas estatales a Valencia después de la inundación. La respuesta del régimen es cesar a Trénor, a Joaquín Maldonado, presidente del Ateneo Mercantil, y forzar a la empresa editora del periódico a hacer dimitir a su director. Le sucederá José Ombuena, reconocido como buen periodista y escritor, hombre ponderado y culto, pero del que también hay que señalar su procedencia de las páginas del diario del Movimiento y su sintonía personal y de amistad tanto con Rincón de Arellano como con Alfredo Sánchez Bella, ministro de Información y Turismo desde 1969.

La edición del Almanaque del último año de los 60 mantiene su estructura tradicional. Cuenta con firmas prestigiosas como Enrique Soler Godes, Vicente Garín Llombart, José Corts Grau, y con la colaboración tradicional del escritor Fernando Vizcaíno Casas, afincado en Madrid y amigo de infancia de Ombuena, que traslada evocación y nostalgia de la Valencia de su juventud en cada almanaque. Sin embargo, no se ha plasmado todavía el cambio.

Un joven Francisco Pérez Puche, que más tarde se ocupará durante años de una minuciosa y crítica vida municipal, firma "La gran noticia", sobre la llegada del hombre 
a la luna; y la más joven todavía Consuelo Reyna, por aquellos años en Madrid trabajando en Colpisa, aporta "El negocio musical de la Navidad", abundando en un tema, la crónica musical, de la que también se ocupaba en la agencia de noticias, y que comenzará a llevar cuando se incorpora, dos años más tarde, a la redacción de Las Provincias.

El Almanaque de 1970, recoge en sus primeras páginas de Actualidad Valenciana la concesión de "la Flor Natural al poeta Vicente Andrés Estellés, redactor-jefe de Las Provincias", y publica en su página 181 Vespres del cant, fragmento del poema "Raons personals" que obtuvo el premio dels Jocs Florals.

Pérez Puche se ha incorporado ya a la crónica municipal, y desde este capítulo el Almanaque reconoce que "en el plano local, 1970 fue para Valencia un año interesante [...] Con la primera reunión plenaria del año llegó la primera novedad: las sesiones comenzaron a ser públicas, con el libre acceso de prensa y ciudadanos..." Es en esta crónica donde aparece una referencia que marcará una de las líneas editoriales del periódico en los años venideros: el tema del Saler y la Albufera, que Pérez Puche aborda como "posiblemente, el tema más polémico del año".

La estructura de la publicación empieza a añadir temas: aparece "Ventana al exterior", donde desde entonces aparecerá un resumen anual de política exterior que llevaba el periodista Fernando Herrero.

Mientras tanto, el periódico empieza a publicar en febrero una serie de entrevistas sobre el futuro de Valencia. En ellas, donde se abordaba también el desarrollo urbanístico y la expansión del turismo, laten una serie de quejas ya tradicionales entre la burguesía valenciana sobre el estado de postración de Valencia y lo valenciano. El recién nombrado decano de la Facultad de Derecho, Manuel Broseta, que en poco tiempo será un referente en la vida editorial del periódico, dirigió un informe encargado por la Caja de Ahorros de Valencia sobre las perspectivas de desarrollo para la región: el informe Prevasa. Sobre este informe, Broseta declara al periódico que "hay una cosa que sí ha cambiado en Valencia: es la toma de conciencia. Hace unos años, Valencia estaba adormilada, pero ahora se ha dado cuenta de su problema [...] se es consciente de que hay que tomar soluciones y ya se van produciendo" (Pérez Puche, 2001). El mismo periodista experto en temas municipales señalará en el almanaque de 1971 que "Valencia es una ciudad que vive agobiada por unos problemas muy superiores a sus posibilidades, tanto económicos como de gestión... la actividad escuetamente municipal se ha visto muy atada y si se han conseguido realizaciones de interés ha sido merced al concurso y la ayuda de algunos ministerios. ("Valencia en 1971: un discreto año de realizaciones", Almanaque de Las Provincias, 1971, p.339). Y concluye, 
Si realmente el III Plan de Desarrollo es puesto en vigor con todas sus previsiones y si la ley de Administración Local da las posibilidades de gestión que de ella se espera, la vida municipal de Valencia podrá salir de su etapa gris y administradora... En este sentido, es más que probable que el año que va a empezar signifique para Valencia la definitiva rotura de los moldes... y con ello, el comienzo de lo que muy bien podría ser una segunda expansión, tras aquel punto, ya histórico, de la riada de 1957. Confiemos, pues, y estemos alerta.

(“Actualidad Municipal: Punto final”, Almanaque de Las Provincias 1971, p.347)

Martín Domínguez aludía al clamor de lo inanimado frente al silencio y cobardía de los hombres en el discurso que le valió su fin como director del diario en el que llevaba años al frente. La riada del 57 y el olvido de Valencia provocó el discurso en el inocuo marco de la proclamación de la Fallera Mayor que tanto indignó al poder: "Cuando enmudecen los hombres, hablan las piedras". Doce años después, las mismas páginas del periódico, las colaboraciones en su Almanaque, y su línea editorial, hacen hincapié en la vieja queja: que Valencia pueda salir de "su etapa gris y administradora". Y se apuesta por ello.

En 1972 la periodista María Consuelo Reyna se ha incorporado a la redacción, y sustituye en la subdirección a Vicente Badía, que se jubila. Según recuerda Pérez Puche, se evidencia entonces que va a haber cambios; se amplía el abanico de temas y de colaboradores, y Las Provincias empieza a ser el reflejo de la transformación valenciana de los años 70 . Según reconoce la propia Reyna "no se trata de un plan organizado. Lo que hago es apostar por la gente que conozco y atraerla al periódico. José Ombuena pertenece a una generación y tiene colaboradores en el periódico; yo hago lo mismo con gente de mi generación" (Pérez Puche, 2001).

Y efectivamente, la Redacción y el propio despacho de Consuelo Reyna, se abren, con la aquiescencia del propietario de la empresa, su padre, y del director del periódico, Ombuena. Por otro lado, las cifras de ventas confirman el buen camino.

Desde que se hace cargo de la confección del Almanaque, el enfoque de María Consuelo Reyna y de la "gente de su generación" se hace evidente en su estructura. El Índice del viejo almanaque ha cambiado. A las páginas de Actualidad Valenciana, con artículos mucho más centrados en temas clave (el patrimonio urbano, el Ayuntamiento, el desarrollo industrial valenciano), se unen apartados específicos como Universidad, Agricultura o Economía. En ellos, aparecen firmas que serán determinantes en la historia política y social de la transición valenciana: Manuel Sánchez Ayuso, Manuel Girona, Damià Mollà, Trinidad Simó, Francesc de Paula Burguera, Manuel Broseta, Aurelio Martínez, Sanchis Guarner o José María del Rivero.

1973 es el año en que Las Provincias, con el equipo Reyna, Pérez Puche y Penalba, "echa el resto" en la defensa de la Dehesa del Saler. Son días y días de seguimiento, 
editoriales, fotografías del fotógrafo José Penalba, entrevistas y estilo directo, hasta concienciar a una opinión pública que no veía el desastre.

El Almanaque lo recoge: Dentro de los grandes temas de la vida municipal se resalta la urbanización del Saler y el destino del cauce del Turia. El naturalista Ignacio Docavo critica la enorme escasez de espacios verdes en la ciudad. Pérez Puche hace una alarmada crónica de "La Dehesa al día", anunciando "ya se construyen hoteles y apartamentos", y María Consuelo Reyna, con su estilo claro y directo arremete en dos artículos sucesivos en el periódico, que se recogen en el Almanaque ("La Dehesa", Almanaque de Las Provincias 1973, pp.95-101).

La tan comentada repoblación de la Dehesa es una de las cosas más dolorosamente cómicas que he oído en los últimos tiempos. Es como si alguien dijese: Vamos a derribar la catedral de Burgos y en su lugar haremos una iglesia más acorde con las directrices del Concilio Vaticano II. Que piensen que la Dehesa también es una obra de arte de la naturaleza"...

Antes de empezar a escribir este comentario, he vuelto a la Dehesa. La he recorrido palmo a palmo, más a fondo que nunca y.... creo haberme quedado corta: han destrozado el paisaje. La Dehesa, a no ser que se detuviesen radicalmente las obras, ya no tiene solución.

Se abordan en este número la crisis de la Universidad y los últimos coletazos de la censura a estudiantes y profesores. Se denuncia el incierto destino de la Facultad de Económicas de Valencia, que el periódico insiste en mantener para una ciudad en expansión. Se reflejan y comentan datos económicos y de población. Francesc Burguera incide en la necesidad de promover y defender la producción de naranja y su exportación. Broseta escribe sobre "los trabajadores españoles y el Mercado Común", mientras Vicent Andrés Estellés repasa, en valenciano, las excelencias de Castellón y Alicante. Mientras, el incisivo y breve estilo de Consuelo Reyna reniega: "Sureste y Levante”, “¿tanto cuesta decir región valenciana, Reino de Valencia, país valenciano o simplemente Valencia? ("Sureste y Levante", Almanaque Las Provincias 1973, pp.207208).

En este Almanaque de 1973 las distancias marítimas y los horarios de ordinarios han quedado relegados por una información más actual y necesaria: excursiones por la región valenciana. El Juicio Universal ha desaparecido de las páginas del Almanaque. 


\subsection{4-1980. Las Provincias y su papel en la transición en Valencia.}

La portada del Almanaque de 1974 es elocuente: el tronco de un pino en el que se ha clavado un cartel que reza: "Respetad este parque. Denunciad a los que lo maltraten". Y en el interior se apostilla "El Saler fue, también a lo largo de 1974, uno de los grandes temas polémicos. A lo largo del Almanaque, queda constancia de ello".

El formato se moderniza. Consuelo Reyna sabe reconocer el potencial gráfico de un magnífico fotógrafo que ha sucedido a su padre en el periódico: José Penalba. Sus fotografías de página entera ilustran cada mes la llamada Actualidad valenciana.

Se incluye un apartado conjunto de Economía y Agricultura; un apartado de Editoriales y un capítulo muy relevante del cambio que se intuye: Las ideas y los hechos, en el que se cuentan aportaciones de Josep Lluis Blasco ("Los intelectuales y la política"), Manuel Broseta ("Universidad libre y Universidad despolitizada"), Trinidad Simó ("Ecología y desarrollo industrial. ¿Incompatibles?"), Vicent Soler ("Després del Saler, el riu”) y "La veu del nostre poble", del Profesor Broseta.

Amando de Miguel intenta aclarar "Lo que va a pasar", y en este sentido, el Almanaque recoge un extenso apartado bajo el epígrafe "España y su futuro", fruto de entrevistas que el periódico realizó a lo largo de varias semanas a personalidades valencianas de distintas tendencias, sobre su visión del futuro de España y el futuro de Valencia.

Nuestro Almanaque de 1975 llega a las manos de nuestros lectores marcado por la huella de Franco [...] Días después, el 23 de noviembre, S.M. el Rey don Juan Carlos I hacía un llamamiento a todos los españoles sin excepción... Nosotros, los que hacemos Las Provincias nos sumamos a los dos Ilamamientos [...]Con 1975 termina la época de una figura histórica sin posible parangón...

(“La huella de Franco", Almanaque de Las Provincias 1975, pp.V-VIII)

Termina una época y empieza una nueva en la que la redacción de Las Provincias se abre, aunque, como recuerda María Consuelo Reyna, "no fue en ningún momento un proyecto definido del periódico, sino que vivíamos aquellos tiempos en su día a día, y cada uno lo vivía como quiso". Y sigue evocando: "había muchísima ebullición. Veíamos que íbamos a sufrir una transformación total y que no sabíamos cómo enfocar. Todos, del primero al último, habíamos nacido en pleno franquismo. Por eso, a veces, hacíamos las cosas que hacíamos, porque no sabíamos calibrarlas".

La incorporación al periódico de una joven plantilla de periodistas y la entrada de firmas procedentes de la Universidad, la economía, abanderados de temas hasta entonces opacos como el feminismo, el ecologismo o filólogos de la talla de Sanchis 
Guarner, afloran un nuevo estilo al viejo rotativo, de la mano de Consuelo Reyna. Y se plasma en las páginas de su Almanaque.

Así, el propio número de 1975 celebra el empleo de la lengua valenciana en el pleno de la Diputación o deplora el final de las "cenas políticas" que se venían celebrando en Valencia desde 1971, y de las que Las Provincias era puntual cronista y, en ocasiones, invitado.

Al Almanaque de 1975 se incorporan colaboradores relevantes en la nueva vida política valenciana: Joaquín Muñoz Peirats, el abogado Vicente Montés, creador de la Escuela Valenciana de Derecho Civil, o el sociólogo Amando de Miguel que da cuenta de una conferencia de Vicent Ventura: "el País Valenciano es Vicente Ventura. En la conferencia de anoche se me hizo realidad esta caprichosa asociación" ("El complejo de Cid Campeador", Almanaque de Las Provincias 1975, pp.251-253)

María Consuelo Reyna, que ha inaugurado su famosa columna "País", reivindica el orgullo de pertenecer a Valencia, y critica sus carencias, bajo un título que apunta tendencias que años más tardes se han revelado dramáticas para esta ciudad: "Faraonismo" (Almanaque de Las Provincias, 1975, pp.227-228).

Si añadimos a este número colaboraciones como la del joven economista Vicent Soler, que había inaugurado hacía dos años en el periódico su sección "Pulso económico", la de Vicent Andrés Estellés bajo el título "Una conferencia, una ciutat, un país", la reflexión sobre el momento cultural valenciano de Amadeu Fabregat, o "Els xiquets i la llengua", de Manuel Sanchis Guarner, queda muy claro que el viejo diario conservador "abre sus páginas y se deja impregnar por una parte de la sensibilidad aperturista de un país que está cambiando" (Bordería, 2000: 286).

Pese a que el diario sigue manteniendo en sus páginas un mesurado tono oficialista, sobre todo en política nacional, el peso del lector tradicional del periódico, la burguesía valenciana, y la necesidad de alcanzar sus peticiones económicas, hacen que el discurso del periódico incida en todo "lo valenciano" y de igual modo se refleja en las páginas anuales de El Almanaque:

"Valencia tiene desgracia en las altas regiones gubernamentales. Mientras otras provincias miran prevenidas sus aspiraciones... Valencia hace infructuosos esfuerzos para obtener lo que de justicia se le debe...

Si al pie de esta cita pusiéramos una fecha reciente, la de este mes de abril de 1976, es muy probable que el lector no reparara en el engaño; La frase, sin embargo, es antigua. Acaba de cumplir, como si nada, ciento diez años. Fue escrita por la redacción de Las Provincias, en enero de 1866"

(“Hoy como ayer", Almanaque de Las Provincias 1976, pp.179-181) 
El periódico está impregnado de ansiedad, de expectación, y de reivindicaciones de un cierto autogobierno. Llegan a la redacción de forma continua políticos nuevos y viejos. Las noticias de la prensa de Madrid se comentan en la redacción mientras se espera el cierre. $Y$ los acontecimientos se suceden a una velocidad que los años anteriores no habían contemplado: Salvador Barber firma "El año más largo", en el que detalla mes por mes manifestaciones pro-amnistía, huelgas, mítines, constitución de la Taula de Forces Polítiques i Sindicals y creación de nuevos partidos. (Almanaque de Las Provincias, 1976, pp.105-122).

Abierto a la ciudad viva, el periódico ha incorporado desde hace un par de años, una nueva sección "Aquí los barrios", que sigue con detalle el periodista Antonio Luque. Comienza también a incorporarse al Almanaque, junto con colaboraciones que rescatan figuras políticas del pasado democrático valenciano. Emilio Attard se ocupa de reivindicar la figura del líder de su viejo partido, la Derecha Regional Valenciana, Luis Lúcia.

Hasta 1978 tanto el periódico, como su suplemento anual, el Almanaque, mantienen el tono progresista y de apertura, que todavía encaja con la voluntad de cambio de un sector relevante de la burguesía valenciana, que no tenía empacho en mantener aspiraciones regionalistas/nacionalistas frente al poder del gobierno central; aspiraciones que en los lejanos años 30 también sustentó la burguesía financiera y agrarista de Ignacio Villalonga.

Para Manuel Broseta, cada vez más presente en las páginas del periódico, "soy de los que estiman que, en términos absolutos, la apertura no se está realizando en la profundidad y con la velocidad que era de desear en todos los sectores de la vida política y social" (Bordería, 2000: 287).

Y desde el periódico decano se pone todo el empeño: El Almanaque de 1977 se centra en la lucha por la autonomía, con colaboraciones de Broseta, Sánchez Ayuso, Maldonado, Albiñana, Noguera de Roig, Emilio Attard, y la propia Consuelo Reyna ("La Generalitat espera", Almanaque Las Provincias 1977, p.337).

“Las Provincias dóna, amb motiu d'aquesta important ocasió, el text íntegre del parcialment conegut poema de Vicent Andrés Estellés, -Poble- Cal dir que està signat a 1975, quan el despertar autonomista del poble valencià es ja irreversible.

Més enllà, però, del seu indubtable valor literari, encara estant moltíssim, hi ha de reconeixer la veu del poble, d'un poble que s'acosta al seu moment, hui maiteixa"

(“Poble. Al País Valencià”. Almanaque de Las Provincias 1977, pp.479-483) 
En las elecciones generales de 1977, la UCD es derrotada en Valencia frente a los partidos de izquierda. El partido de Adolfo Suárez, que en Valencia se había constituido con el Partido Popular Regional Valenciano de Emilio Attard, intenta hacerse fuerte para ganar las elecciones generales y municipales de 1979. Para ello, busca la colaboración del valenciano Abril Martorell, y de Manuel Broseta y condicionar el proceso de elaboración del Estatuto de Autonomía. Se elimina del partido a los miembros liberales como Francisco de Paula Burguera, José Antonio Noguera de

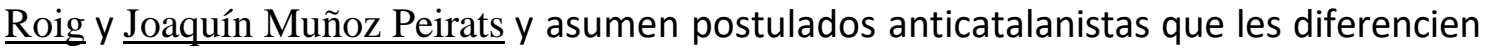
del sector liberal apartado. Encuentran eco en Las Provincias, que desde entonces vuelve a posturas conservadoras "como le es natural" (Pérez Puche, 1998: 266).

Aunque un editorial recogido en el Almanaque, señala que "Las Provincias, que nació hace más de un siglo para servir a este pueblo, tiene que aplaudir este primer brote institucional que es el Consell del Pais Valenciano" ("Hacer País", Almanaque de Las Provincias 1978, pp.191-192), la edición de 1980 recoge el famoso artículo aparecido en el periódico en mayo de 1980, “Adiós al País Valenciano". En él, la periodista rebate con firmeza un término que había venido usando en sus columnas, y que hacía propio el periódico y sus colaboradores,

Si algo me importa muy poco en este mundo es rectificar cuando creo que me he equivocado, y hoy voy a hacerlo... País valenciano podía haber sido la denominación... si detrás de este nombre no hubiera un proyecto político que lo que pretende es anular nuestra región.

Quizá, como dice Fuster, yo pertenezca a esos puristas que prefieren hablar en nombre de la historia.., todo antes que secundar una muy hábil e inteligente maniobra para borrar a nuestra Valencia del mapa e integrarla en esa Gran Cataluña..."

(Almanaque Las Provincias 1980, pp.279-280)

Con todo, la tradición y la calidad del Almanaque se ha mantenido los últimos años de la década. Se sigue con atención la vida municipal. El signo del Ayuntamiento cambia en 1979 y se suceden en pocos meses dos alcaldes socialistas. El Almanaque reproduce la carta enviada por Fernando Martínez Castellano, que dimite al cabo de cinco meses para dar paso a un alcalde que será significativo en la vida y la fisonomía de una ciudad nueva: Ricard Pérez Casado ("Cinco meses... Valencia”, Almanaque de Las Provincias 1979, pp.93-94).

Se sigue el Consell preautonómico y las vicisitudes de la vía valenciana a la autonomía. Se incorporan firmas de UCD como la de Jaime Lamo de Espinosa ("UCD: un voto a favor de la esperanza", p.315). 
La procesión cívica del 9 de octubre ha sido cruenta, con agresiones tanto al alcalde Pérez Casado como a otros políticos participantes. La Batalla de Valencia está activa, y Las Provincias, quiéralo o no, es parte en ella. En esta línea, pero deplorando la violencia, Consuelo Reyna recoge en el Almanaque una columna publicada en el diario, que todavía titulaba "País":

Lo de ayer debe ser tomado como una amarga lección [...] Un gobernante no puede obcecarse en la defensa de unas ideas que no conectan con el pueblo al cual tiene la misión de dirigir, y si humilla, crispa e insulta al pueblo que lo votó, lo único que logrará es hacer más y más grande el abismo entre gobernantes y gobernados.

(“Un triste 9 de Octubre”. Almanaque de Las Provincias 1979, pp.339-340)

La crónica del mes de enero en el Almanaque de 1980 se inicia con un explícito titular: "El Consell suprime la bandera cuatribarrada". Los vaivenes de la política preautonómica ocupan las páginas, junto a un capítulo nuevo: "En torno a la Autonomía y la Lengua Valenciana", en el que junto a las firmas de Attard, Broseta, Manuel del Hierro o Manuel Girona, se incluyen dos artículos centrados en la lengua valenciana: "Polémica en el Senado sobre la lengua valenciana", de Milagro Heredero, y "El manipulado desmarque de un sentimiento", de Pascual Martín Villalba, Presidente del Grup d' Acció Valencianista.

En 1980 el Almanaque ha cumplido cien años. El escritor y periodista Vicente Vidal Corella, que inició su andadura profesional en el Diario de Valencia en los años 30, resalta que

Hace ahora cien años,... don Teodoro Llorente Olivares y don José Doménech Taberner iniciaban la publicación continuada de una obra que sería una verdadera institución erudita y literaria: el Almanaque de Las Provincias... Aquel Almanaque para 1880 marcó la pauta para la publicación -corregida y aumentada- en años sucesivos.

("Un siglo de la vida y cultura valencianas", Almanaque de Las Provincias 1980, pp.365-368)

En 1980 ya no hay "primavera" en Las Provincias. Valencia -aún sin definirse como País, Región, Reino o Comunidad- no ha estrenado autonomía. El periódico, como empresa, sigue creciendo, en estos momentos sin competencia, y la influencia de su subdirectora, Consuelo Reyna, también. Se le lee, se le teme y se le escucha. Los políticos continúan acudiendo a su despacho, que sigue abierto. Bordería señala que las demandas que desde los años 70 recogía el periódico "recordaban con absoluta fidelidad las preocupaciones del mismo grupo social por los años cincuenta, cuando el 
director Martín Domínguez había iniciado su particular enfrentamiento con la censura" (Bordería, 2000: 288).

Ahora, la libertad informativa permitía publicar esos anhelos, pero no cambiaba sus principios. Y, por cierto, en los almanaques de 1978 a 1980 ha vuelto a aparecer el Juicio Universal al final de su edición.

\section{Conclusiones}

El Almanaque del diario Las Provincias, deudor de las publicaciones de carácter popular que se desarrollaron en España desde el siglo XVIII, puede ser encuadrado en el género de prensa literaria valenciana, en cuanto a la calidad y diversidad de sus colaboraciones, la defensa en sus páginas del valencianismo literario y cultural, y a la expresión, en definitiva, del binomio periodismo-literatura.

Por otro lado, sus ediciones anuales reflejan la vocación integradora y plural que, en su manifiesto fundacional, recogía el periódico Las Provincias, y que en las páginas del Almanaque se evidencia con un amplio espectro de colaboradores literarios, artísticos y de opinión, que la rigidez y control de las páginas del periódico no permitían.

Presenta el valor añadido de recopilar un sinnúmero de artículos en lengua valenciana, incluso en los años cuarenta y cincuenta, con firmas como la del propio Joan Fuster, Vicent Andrés Estellés o Manuel Sanchis Guarner.

Es indudable su importancia como fuente de estudio de ciento cincuenta años de historia valenciana, tanto como crónica detallada de acontecimientos, como de recuperación de personajes que colaboran en sus páginas, muchas veces olvidados.

En la década de los 70, entre el franquismo y la transición a la democracia, El Almanaque es fiel reflejo de la propia evolución ideológica del periódico, y una galería inestimable de colaboradores activos en nuestra reciente historia. Sociólogos, urbanistas, economistas y políticos de todas las tendencias se dan cita en sus páginas, con una nueva óptica en el viejo diario conservador y en su compendio anual que dirige la subdirectora, Consuelo Reyna, periodista, empresaria y propietaria. 


\section{Referencias bibliográficas}

ALTABELLA, J. (1970): “Las Provincias. Eje histórico del periodismo valenciano 18661969”, Madrid, Editora Nacional.

ARCHILÉS CARDONA, F. (2006): “Hacer región es hacer patria. La región en el imaginario de la nación española de la Restauración" en Ayer, Marcial Pons Editores, pp.121-147.

BARRERA, C. (1995): Periodismo y franquismo de la censura a la apertura. Madrid, EIUNSA.

BORDERIA, E. (2000): La prensa durante el franquismo: represión, censura y negocio, Valencia (1939-1975), Valencia, Fundación Universitaria San Pablo, CEU.

- (2006): “Aperturismo avant la lettre en la prensa del franquismo: la burguesía valenciana y la voz disonante de Las Provincias, 1949-1975" en VI Encuentro de Investigadores del Franquismo. Universidad de Zaragoza.

CRESPO, A. (2005). "Las Provincias: un diario conservador durante la Transición en Valencia (1972-1982) en Actes del Congrés "La Transició de la dictadura franquista a la democracia" Barcelona.

CORTÉS, S. (1991): “Premsa literaria valenciana de postguerra: El cas de L'Almanaque de Las Provincias (1940-1951)", en Caplletra, Revista Internacional de Filología, no. 10 , pp. 41-50.

GUILLAMET, J. y SALGADO, F. (2014): El periodismo en las transiciones políticas: de la Revolución Portuguesa y la Transición Española a la Primavera Árabe, Madrid, Biblioteca Nueva.

IRANZO, A. (2014): "Prensa y poder. Las Provincias, actor político central de la Transición valenciana". Historia y Comunicación Social, no 19, pp. 535-544.

MATEU, A. y DOMINGUEZ, M. (2011): "Inicios del columnismo ambiental en la prensa española. La campaña de Las Provincias sobre la urbanización del Saler", Zer, no 30, pp.171-187.

PAREJA, M. (2013): El periódico Mediterráneo durante la transición española (19751982), Castelló, Universitat Jaume I. Servei de Comunicació i Publicacions.

PEREZ PUCHE, F.: “Los medios informativos en la Transición” en GARRIDO, V., MARTIN, J., y SOLER, M. (eds), 1998: La transición política en la Comunidad Valenciana. Valencia: Fundación Profesor Manuel Broseta. pp.261-275.

- (2001): Tal como éramos. La Valencia de los años 70, Valencia, Carena Editores. 
SAZ, I. (2007): "Franquismo y democracia en Valencia" en Actas del Simposio "Reino y Ciudad, Valencia en su Historia". Fundación Caja Madrid. pp. 601-640

SENSO, C. (2014): "Parlaments de paper. Valencia Semanal i la Transició a la democracia al país Valencià" en Afers no 79, 2014, pp.771-792.

SEOANE, M.C. y SAIZ, M.D. (2007): Cuatro siglos de periodismo en España. Madrid, Alianza Editorial-

SOLER, V. (2011): L'ofici de raonar, Valencia, Publicacions Universitat de València.

XAMBÓ, R. (1995): Dies de Premsa. La Comunicació al País Valencià des de la Transició Política. València, L’Eixam Edicions. 